\title{
Surmounting the barrier: advances and challenges in transdermal drug delivery
}

The skin represents both a logical target and a significant challenge to researchers in the field of therapeutic delivery. The very obstacles that our bodies have evolved to protect us from harmful compounds are those that researchers must overcome in order to deliver drugs to the bloodstream, and this conflict has resulted in transdermal drug delivery developing into one of the most innovative and exciting areas in the field of therapeutic delivery. While transdermal delivery has been steadily used in a clinical setting for small-dose lipophilic drugs, recent research has seen clinical products developed and trials set in motion for a wide range of novel delivery systems [1].

In this special focus issue of Therapeutic Delivery, we have assembled articles from key opinion leaders in the field of transdermal drug delivery. These pieces aim to highlight the challenges that researchers face when attempting to target the skin as a mode of delivering drugs systemically, while also providing cutting-edge insights into recent advances.

Our guest editor for this issue is Vishal Sachdeva, Scientist in the Drug Delivery Sciences Department at Allergan, plc (CA, USA). For the past approximately 5 years, Sachdeva has been involved in the development of oral, parenteral and dermal dosage forms in pharmaceutical industry. Sachdeva has been an active member of the American Association of Pharmaceutical Scientists (AAPS), particularly as a member of their Modified Release Focus Group and has presented his research work in various conferences, notably for AAPS and Controlled Release Society. While studying for his $\mathrm{PhD}$ in Pharmaceutical Sciences from Mercer University, College of Pharmacy and Health
Sciences (GA, USA), his research work consisted of formulation development and evaluation of passive and active technologies (iontophoresis, sonophoresis and microneedles) for dermal and transdermal delivery of therapeutic drug molecules.

With Sachdeva's kind assistance and support, we have compiled exciting content from across this dynamic field of research. S Giannos' special report highlights the complexities of developing transdermal drug delivery, particularly how current challenges will translate into future products [2]. Kolli provides an overview of one such developing technology: microneedles, an area where some innovative designs are still in their infancy, but a few others have made it to the marketplace [3]. In an insightful review by Chen, Bowersock, Weeratna and Yeoh evaluate the current and emerging technology available for intradermal vaccination, a promising area of research with the potential to increase patient compliance and convenience for a wide range of stakeholders [4].

A perspective from the cosmetic industry is provided by Scott and Banga, while Katikaneni presents the potential of transdermal delivery for biopharmaceuticals $[5,6]$. Methods for screening transdermal formulations in vitro are discussed in a review article by Tsai, Lee and Michniak-Kohn, and the necessity of chemistry, manufacturing and controls in preventing problems with transdermal delivery systems are reviewed by Goswami and Audett [7,8]. Correlations between in vitro and in vivo testing are addressed by Paudel, Milewski and Ghosh, an important step for researchers aiming to move their device to tests in human subjects [9].

The issue concludes with a review article from the guest editor, Sachdeva, and his col-

\section{Stella Bennett}

Future Science Group, Unitec House, 2 Albert Place, London N3 1QB, UK s.bennett@futuremedicine.com 
league Singla, who review the progress made in lipidbased systems for transdermal drug delivery, as well as presenting a future perspective for research in the field [10].

We hope that you find this special focus issue of Therapeutic Delivery interesting and informative, and that the expert insight provided by our authors will drive further research into this dynamic and rapidly evolving field.

\section{References}

1 Prausnitz M R, Langer R. Transdermal drug delivery. Nat. Biotech. 26(11), 1261-1268 (2008).

2 Giannos SA. Identifying present challenges to reliable future transdermal drug delivery products. Ther. Deliv. 06(09), 1033-1041 (2015).

3 Kolli CS. Microneedles: bench to bedside. Ther. Deliv. 06(09), 1081-1088 (2015).

4 Chen D, Bowersock T, Weeratna R, Yeoh T. Current opportunities and challenges in intradermal vaccination. Ther. Deliv. 06(09), 1101-1108 (2015).

5 Scott JA, Banga AK. Cosmetic devices based on active transdermal technologies. Ther. Deliv. 06(09), 1089-1099 (2015).
Financial \& competing interests disclosure

$\mathrm{S}$ Bennett is an employee of Future Science Group. The author has no other relevant affiliations or financial involvement with any organization or entity with a financial interest in or financial conflict with the subject matter or materials discussed in the manuscript apart from those disclosed.

No writing assistance was utilized in the production of this manuscript.

6 Katikaneni S. Transdermal delivery of biopharmaceuticals: dream or reality? Ther. Deliv. 06(09), 1109-1116 (2015).

7 Tsai P-C, Lee S, Michniak-Kohn B. In vitro methods for screening transdermal formulations. Ther. Deliv. 06(09), 1063-1070 (2015).

8 Goswami T, Audett J. Chemistry, manufacturing and controls (CMC) in passive transdermal drug delivery systems (TDDS). Ther. Deliv. 06(09), 1071-1079 (2015).

9 Ghosh P, Milewski M, Paudel K. In vitro/in vivo correlations in transdermal product development. Ther. Deliv. 06(09), 1117-1124 (2015).

10 Singla SK, Sachdeva V. Current and emerging lipid based systems for transdermal drug delivery. Ther. Deliv. 06(09), 1063-1070 (2015). 